\title{
Heutagogy: The Most Holistic Approach Utilizing Technology in Learning
}

\author{
Fitria Lapele ${ }^{1, *}$, Badrun Kartowagiran ${ }^{2}$, Haryanto Haryanto ${ }^{2}$, Eko Wahyunanto \\ Prihono $^{1}$
}

\author{
${ }^{1}$ Faculty of Teacher Training and Education, Institut Agama Islam Negeri Ambon, Indonesia \\ ${ }^{2}$ Postgraduate Program of Universitas Negeri Yogyakarta, Indonesia \\ *Corresponding author. Email: fitria.lapele91@gmail.com
}

\begin{abstract}
This research discusses the heutagogical approach, which is the most holistic approach in the era of Distance Learning that utilizes technological developments. Students have the independence to negotiate, determine to learn, and how it will be learned. This current research aims to expose and offer a heutagogical approach. Therefore, the learning continues to run optimally. The research method used was literature observation and review. It was conducted by making problem formulation, data collection, evaluation, analysis data interpretation, and public presentation. This study revealed that by implementing a heutagogical approach, distance learning could be delivered better, and the students construct innovative learning. Moreover, this approach will create double-loop learning. Students realize the problem, do the action, result in the outcome, and influence learning belief and action. Furthermore, some elements support this approach, such as approval, facilitators, choice, agreement, review, assessment, and feedback.
\end{abstract}

Keywords: Heutagogy, Learning Approach, Technology.

\section{INTRODUCTION}

The pandemic is a disaster for the whole world. In March 2020, the Ministry of Education and Culture in Indonesia was concerned about implementing education policies in the era of coronavirus disease. All learning process is conducted from home (Distance Learning). Exploiting this learning requires an approach supported by technology.

The teaching-learning process can be run online or offline in distance learning. In online education, lecturers and students interact simultaneously, and the same application or internet platform interacts like conventional learning [1], [2]. Meanwhile, offline learninglecturersers upload material via the web, send it via electronic mail (e-mail), or upload it via social media. Students can then download it. They learn independently without being bound by time and place.is

Education nowadaystion nowadays is an innovation where humans use digital open-source, content, source content, and global classrooms to apply life-long learning, flexible education systems, and personalized learning to play a better role [3]. Regarding technologybased learning in universities, if the measurement is "can be done," it cannot be denied that all universities can do it. However, whether the quality of technologybased learning can be fulfilled as desired or not. Of course, it will be difficult to answer because it involves many factors, requires the involvement of various parties, and optimal preparation.

Students become the source of strength to the success or failure of the online learning process [4]. This is because online, non-direct, network-controlled, and technologically-based learning requires students to monitor and execute the process. That is why students are referred to as learners in the modern learning model. This is in line with the objective of online learning, which sees the importance of independent learning skills [5], especially in higher schools with an ability to regulate themselves. 
The independence of students to work on assignments with personal creativity sometimes makes lecturers surprised because what students produce is very satisfying [6]. After all, it is beyond the expectations of the lecturer. It turns out that online learning made learning easier with improved results. The results obtained, of course, are inseparable from the skills of students and lecturers in the learning process. Thus, there is a shift in the focus of classroom management from what is usually known as pedagogy to andragogy and develops into heutagogy [7].

The development of management in classrooms from andragogy to heutagogy has fallen behind and is still considered unsatisfactory [8]. Thus, in online classes, heutagogy came into being. Heutagogy is a more general way of teaching students to develop a model of learning that reflects their competence and independence as students [9]. Furthermore, heutagogy is a style of student management that enables students to be autonomous and transformative as adults. The lecturer's role must be a facilitator to help facilitate learning rather than teaching. What needs to be seen as a facilitator is to prepare a learning atmosphere that makes students more active. Heutagogy is a model produced by adopting two teaching methods: humanism and constructivism. Both of the methods emphasize student-centered teaching. There is a difference that humanism emphasizes the importance of routine, intense, and mutual inter-action, while constructivism uses the self-ability of students who are given autonomy to make things suit their needs [10], [11].

Therefore, the researchers are attracted to research pedagogy. Heutagogy is the most holistic approach in the Distance Learning era that utilizes technology developments. It also facilitates the learning process by providing guidance and resources. But still, the learning path and process are the student's right.

\section{RESEARCH METHOD}

This study provides a broad overview of research results, articles, and relevant issues in which the authors try to build heutagogical concepts and heutagogical practices in the educational process [12]. This literature review was conducted by applying some stages; they are (1) formulate the problem of heutagogy approach that involved in the review, (2) collect the pertinent data related to the problem, (3) evaluate the data, (4) analyze and interpret the data, and (5) present the data reviewed [13].

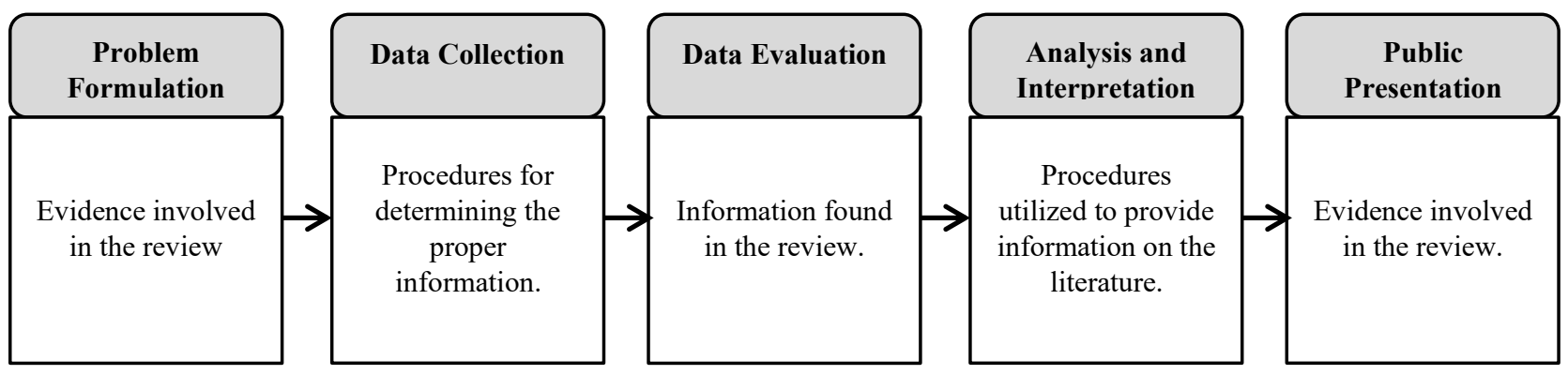

Figure 1 Literature Review Approach

The flow diagram of the stages is shown in Figure 1. Therefore, the finding contributes to the heutagogical approach research as a distance education theory by exploring the possibility of using heutagogy in the utilization of new technologies.

\section{RESULT AND DISCUSSION}

\subsection{The Concept Of Heutagogy}

The concept of heutagogic education, first designed by Stewart of Southern Cross University, is the study of self-determined learning in heutagogy. The idea is an extension of andragogy's reinterpretation, and perhaps the distinction is the same problem when one visibly attempts to differentiate between pedagogy and andragogy [14]. However, there are some differences between the two that mark one over the other. Heutagogy highlights are improving learning how to learn, double-loop learning, universal learning opportunities, non-linear processes, and the proper direction of the learner [15]. Whereas andragogy emphasizes the best way for adults to learn [16]. Heutagogy also involves that educational creativities include skills improvement, that people know how to learn and the given subject itself. In andragogy, the concentration of education is structured, while in heutagogy, all learning contexts combine formal and informal dimensions.

The significant changes in the educational experiences for adults should be designed [17]. This approach is famous as andragogy which differences sharply from pedagogy. The problem both in pedagogy and andragogy is not entirely clear whether the student learns [18]. The self-concept that defines a person's knows is called heutagogy. Heutagogy is based on humanistic theory, and learning approaches originated in the 1950s. It shows that heutagogy is by the needs of 
students in this twenty-first century, especially in the progress of individual abilities and technology.

Humans essentially have a passion for learning. In this regard, people want to learn and naturally do so throughout their lives [19]. Even Rogers strongly argues that teacher-centered education has been going on for too long. He emphasizes learning based on a studentcentered approach with five key hypotheses, they are:

a. Teachers cannot teach others directly; they can only facilitate learning,

b. People learn significantly only for those things they perceive to involve maintaining or improving selfstructure,

c. Experiences that, when assimilated, would involve changes in self-organization tend to be resisted through rejection or distorted symbolization, and self-organization and structure seem to become more rigid under threat,

d. Experiences that are perceived as inconsistent with oneself can only be assimilated if the current selforganization is relaxed and with an expanded scope,

e. The most effective education system to significantly improve learning outcomes threatens self because learning is reduced to achieving a minimum of goals.

Thus, the essence of humans and the rapid rate of change in society was stated as the era of information explosion, an educational approach in which the students themselves determine what and how learning should be conducted [20]. Heutagogy, a study of selfdetermined learning by learners, can be seen as a natural progression from earlier education and may deliver an optimal approach utilizing technology to learn in this twenty-first century.

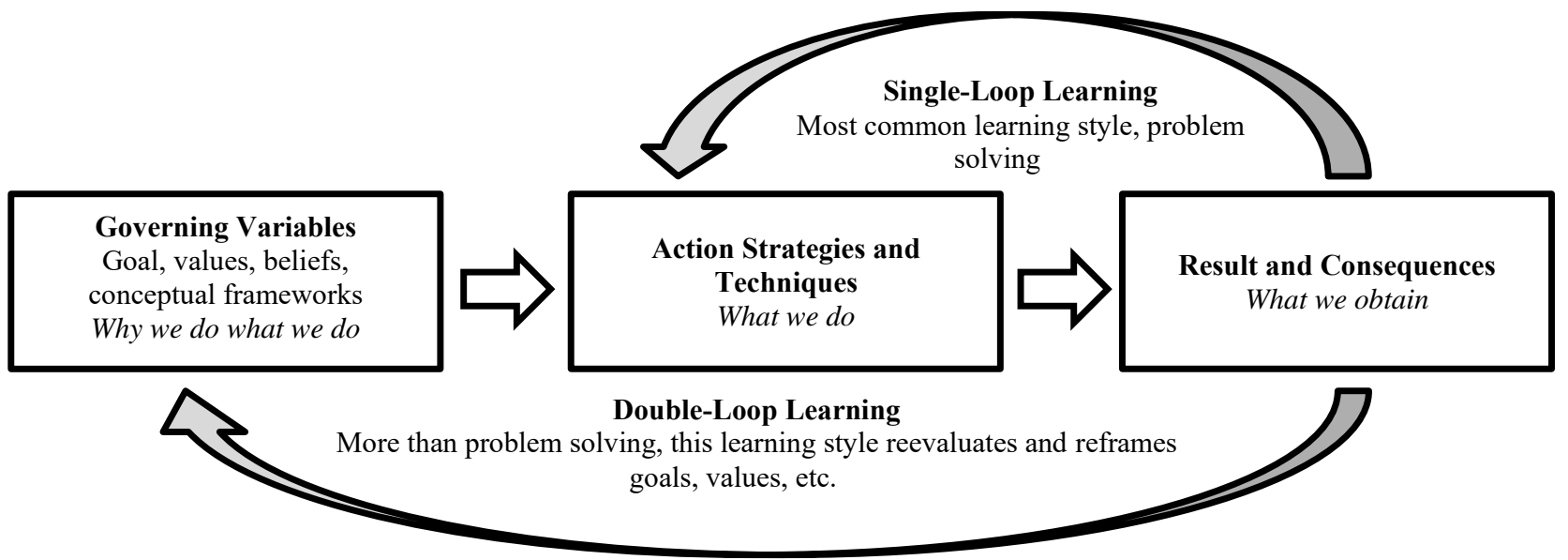

Figure 2 Double-Loop Learning

The heutagogical approach in learning provides experiences in improving personality, independence, and solid learning maturity. The key concepts in heutagogy are double-loop learning and self-reflection [21]. In double-loop education, students consider problems, actions, and the resulting results and reflect on the problem-solving process and how it affects the students' beliefs and activities, as presented in Figure 2. Double-loop learning occurs when students question and test personal values (student reflections on what is needed during learning), and assumptions are central to enhancing knowledge on learning. In double-loop education (learning multiple rounds), students consider the problem (problem), action (action), and the resulting outcome and how it will affect beliefs and actions.

\subsection{Heutagogy in Distance Learning}

Distance learning based on an approach that places the learners as subjects becomes ineffective. One of the limitations of distance learning is the lack of intensive interaction [22]. Therefore, the pedagogical approach will not produce maximum output.

However, distance learning with virtual classrooms makes it easy for students in order to get learning materials and activities because it is determined by technology and require special handling in line with the virtual learning process. Especially nowadays, everything presented in the virtual world is trendy and can encourage curiosity, imagination and finally lead to creativity.

Educational institutions must switch using a pedagogical approach. Place students in the learning center and train them to determine the needs of the material being studied [23]. Involvement, even placing student learning objectives in the formulation of curriculum and materials, is essential. Therefore, when distance learning is applied, students can actively search for material independently. 
The lecturer becomes the interpreter of the material whose ideas come from students. The university must ensure that all the equipment needed is evenly distributed. With these prerequisites, distance education can be effectively carried out and produce maximum output

\subsection{Utilizing Technology in Heutagogy}

Technology is a requirement for innovative learning because it will increase the quality of education, improve productivity/efficiency and access, and increase positive learning attitudes, professional development, and an increase in pro-file/introduction [24]. These things are the basis for the application of technology in heutogogy learning. It will experience changes by global demands.

In this era of globalization, technology, significantly Information and Communication Technology (ICT), are increasing, which forces the world of education to have positive innovations for the advancement of education. One of the functions of educational technology is that it can change the conventional way of learning to be nonconventional [25]. In the context of distance learning, both students and lecturers must respond to increasingly sophisticated technological developments that provide a myriad of knowledge [26]. Education needs to use a series of electronic equipment to work more effectively and efficiently.

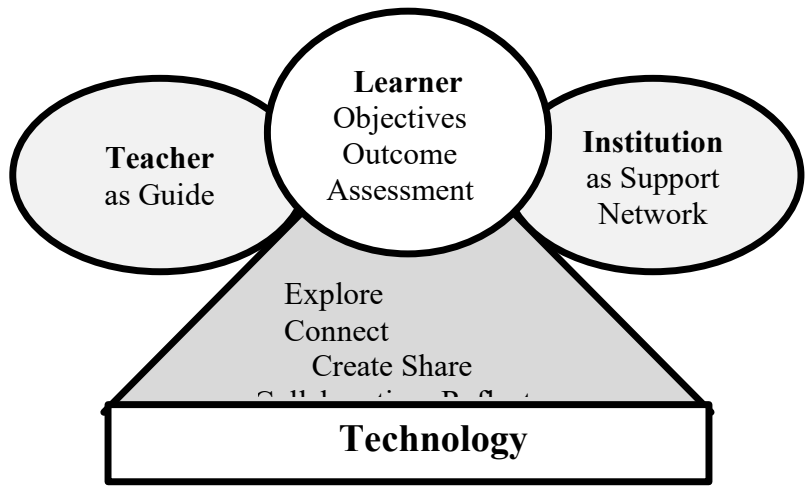

Figure 3 Double-Loop Learning

The learner utilizes technology with objective, outcome, and assessment (see Figure 3). The role of lecturer and institution still works, lecturer as the guide and institution as support network [27].

[28] warned through his writings entitled "The Evolution of Distance Learning: Technology-Mediated Interactive Learning" that to maximize distance education requires a cooperative learning approach supported by maximizing technology. This approach must constantly be upgraded to keep up with the developments and demands of the times.

\subsection{The Implementation of Heutagogy}

In online learning, the students determine the course of the learning process as a form of their knowledge. As a learning process, the lecturer has to design the flexibility of the learning itself. The flexibility in question is setting the time for doing assignments and learning places. In educational technology, the students define the course of the learning process as a form of their knowledge [29]. The flexibility of the learning must be created as a learning process. This flexibility sets the time and place to complete the learning tasks.

The lecturer should develop strong relationships with the students, such as getting students' responses to ensure that the learning process runs efficiently. That strong relationship also creates students' trust in the objective learning process. It means that the learning process creates an atmosphere of comfort and friendliness for the necessities, such as lecturers who trust that what is transferred and done to the students is proper. On the other hand, students rely on what is done as a form of honesty in doing assignments and others.

The next thing needed to run and organize the learning process is to create policies related to the learning process. The approaches should prioritize and consider the students' needs and situation, including the procedure of doing assignments and assessments that both students and lecturers should agree on from the beginning of the learning process. The next one is collaborative. It defines how students in the learning process can learn from all situations.

In addition, collaboration is related to how lecturers and students can use technology to learn. It also related to how the lecturer and students conducted an excellent assessment as part of the learning process designed as a mutually exclusive unit. Collaboration should also be created in collaboration between lecturer and students when the learning process occurs to find and produce learning content.

The fundamentals related to the pedagogical approach provided by [18] are (1) Approval, which requires approval before it is applied to the curriculum using heutagogy as a learning approach. However, it does not require a license outside of official training, (2) Facilitators ensure that students are ready with relevant guidelines in optimized learning, (3) Choice, the facilitator gives choices to students by their capacities and time availability and complexity of the subject, (4) Agreement, where the learning schedule, methodology used, progress review frequency, and the final assessment form, are agreed between students and facilitators. Here, suppose students out of the agreement, the facilitator can remind students about the responsibility (5) Review in which the facilitator needs to regularly monitor the progress and needs of the students, (6) Assessment, where it should be submitted and agreed from the beginning and (7) Feedback. In that case, the facilitator must provide facilities for informal 
discussions, which are helpful to the students with the exchange of students' ideas. In addition, Chako (2013) recognizes heutagogy applied to formal learning by emphasizing students as the learners, provided that all students can control what they learn. They will take an important role and participate directly in achieving learning goals.

\section{CONCLUSION}

Heutagogy is a learning approach suitable for distance learning through the use of technology. This approach focuses on students' existence as learners; they always want to know, mature, and be independent. In that learning, the lecturers act as a moderator and limits themselves to providing help. Thus, they only provide guidance and support. Therefore, lecturers should actively communicate with students, believing that students are responsible people. This approach is used in the online learning process. Online learning uses Internet net-work with a remote system and a high degree of learning flexibility and is determined mainly by the students. The presentation method realizes freedom of thought, creativity, and original ideas.

\section{AUTHORS' CONTRIBUTIONS}

The authors confirm contribution to the article as follows: study conception and design: Fitria Lapele; data collection: Fitria Lapele, Eko W. Prihono; analysis and interpretation of results: Fitria Lapele, Eko W. Prihono, Badrun Kartowagiran; draft manuscript reparation: Fitria Lapele, Haryanto. All authors reviewed the results and approved the final version of the manuscript.

\section{ACKNOWLEDGMENTS}

Countless people supported our effort on this article. Several Professors provided invaluable feedback on our analysis and framing, at times responding to emails late at night and early in the morning. As we wrote, several other professors gave helpful advice. We are grateful to all those who have had the pleasure to work on this and other related projects.

\section{REFERENCES}

[1] T. Loughland and N. Ellis, A common language? The use of teaching standards in the assessment of professional experience: Teacher Education Students' Perceptions., Aust. J. Teach. Educ., vol. 41, no. 7, pp. 56-69, 2016.

[2] G. Basilaia and D. Kvavadze, Transition to online education in schools during a SARS-CoV-2 coronavirus (COVID-19) pandemic in Georgia., Pedagog. Res., vol. 5, no. 4, 2020.
[3] P. A. Bishop, J. M. Downes, and K. Farber, Personalized learning in the middle grades: A guide for classroom teachers and school leaders. Harvard Education Press, 2021.

[4] M. Habibi, S. R. Jannah, and F. Firdiansyah, The application of mind mapping technique in teaching english at the eighth grade students'. of state junior high school 19 Tanjung Jabung Timur, English Education study program, Faculty of Education and Teacher Training and The State Islamic University Studies Sulthan Thaha Saifuddin, UIN SUTHA JAMBI, 2021.

[5] L. Song and J. R. Hill, A conceptual model for understanding self-directed learning in online environments, J. Interact. Online Learn., vol. 6, no. 1, pp. 27-42, 2007.

[6] T. J. Stalker et al., A systems approach to hemostasis: 3. Thrombus consolidation regulates intrathrombus solute transport and local thrombin activity, Blood, J. Am. Soc. Hematol., vol. 124, no. 11, pp. 1824-1831, 2014.

[7] C. Kenyon and S. Hase, Andragogy and heutagogy in postgraduate work, in Meeting the challenges of change in postgraduate education, 2010, pp. 165177.

[8] J. A. Rathner and M. A. Schier, The impact of flipped classroom andragogy on student assessment performance and perception of learning experience in two advanced physiology subjects, Adv. Physiol. Educ., vol. 44, no. 1, pp. 80-92, 2020 .

[9] L. Ortiz and J. Jani, Critical race theory: A transformational model for teaching diversity, J. Soc. Work Educ., vol. 46, no. 2, pp. 175-193, 2010.

[10] M. S. Nystul, Introduction to counseling: An art and science perspective. Sage Publications, 2015.

[11] F. MacDuff, K. AlHayki, and C. Linse, Using Progressive I-Can Statements to Promote Learner Confidence in Writing., in English Teaching Forum, 2010, vol. 48, no. 4, pp. 2-11.

[12] L. M. Blaschke, Self-determined learning (heutagogy) and digital media are creating integrated educational environments for developing lifelong learning skills, in The digital turn in higher education, Springer, 2018, pp. 129 140.

[13] K. Azmy, J. Veizer, M. G. Bassett, and P. Copper, Oxygen and carbon isotopic composition of Silurian brachiopods: implications for coeval seawater and glaciations, Geol. Soc. Am. Bull., 
vol. 110, no. 11, pp. 1499-1512, 1998.

[14] A. Hartree, Malcolm Knowles' theory of andragogy: A critique, Int. J. lifelong Educ., vol. 3, no. 3, pp. 203-210, 1984.

[15] R. Crawford, A multidimensional/non-linear teaching and learning model: Teaching and learning music in an authentic and holistic context, Music Educ. Res., vol. 16, no. 1, pp. 50-69, 2014.

[16] S. Long, Various ways of understanding the concept of andragogy, Cogent Educ., vol. 5, no. 1, p. $1496643,2018$.

[17] M. S. Knowles, The Modern Practices of Adult Education: Andragogy versus Pedagogy. Chicago, IL: Association Press, Follett Publishing Co, 1970.

[18] S. Hase and C. Kenyon, Self-determined learning: Heutagogy in action. A\&C Black, 2013.

[19] C. R. Rogers, Freedom to Learn. Columbus, Ohio: Charles E, Merrill Co, 1969.

[20] S. C. Johnston et al., The discussion about advance directives: patient and physician opinions regarding when and how it should be conducted, Arch. Intern. Med., vol. 155, no. 10, pp. 10251030, 1995.

[21] S. Hase and C. Kenyon, From andragogy to heutagogy, multi-base In-Site, 2000.

[22] C. J. Heap and E. Wolverson, Intensive Interaction and discourses of personhood: A focus group study with dementia caregivers, Dementia, vol. 19, no. 6, pp. 2018-2037, 2020.

[23] C. E. Weinstein, Assessment and training of student learning strategies, in Learning strategies and learning styles, Springer, 1988, pp. 291-316.

[24] E. Salas, K. A. Wilson, C. E. Murphy, H. King, and M. Salisbury, Communicating, coordinating, and cooperating when lives depend on it: tips for teamwork, Jt. Comm. J. Qual. Patient Saf., vol. 34, no. 6, pp. 333-341, 2008.

[25] F. A. Mokhtar, Rethinking Conventional Teaching in Language Learning and Proposing Edmodo as Intervention: A Qualitative Analysis., Malaysian Online J. Educ. Technol., vol. 4, no. 2, pp. 22-37, 2016.

[26] A. Wan and J. Ivy, Providing access by integrating computer-aided design in mathematics teacher education courses, J. Digit. Learn. Teach. Educ., pp. 1-13, 2021.

[27] A. L. Williams et al., The power of social networks: A model for weaving the scholarship of teaching and learning into the institutional culture,
Teach. Learn. Inc., vol. 1, no. 2, pp. 49-62, 2013.

[28] C. J. Dede, The evolution of distance learning: Technology-mediated interactive learning, J. Res. Comput. Educ., vol. 22, no. 3, pp. 247-264, 1990.

[29] M. Frank* and A. Barzilai, Integrating alternative assessment in a project-based learning course for pre-service science and technology teachers, Assess. Eval. High. Educ., vol. 29, no. 1, pp. 4161, 2004. 